\title{
Mathematical model of optical signals emitted by electrical discharges occuring in electroinsulating oil
}

\author{
Michat Kozioł ${ }^{1, *}$ \\ ${ }^{1}$ Opole University of Technology, Prószkowska 76, 45-758 Opole, Poland
}

\begin{abstract}
The article presents a parametric model describing the registered distributions spectrum of optical radiation emitted by electrical discharges generated in the systems: the needle- needle, the needleplate and in the system for surface discharges. Generation of electrical discharges and registration of the emitted radiation was carried out in three different electrical insulating oils: fabric new, operated (used) and operated with air bubbles. For registration of optical spectra in the range of ultraviolet, visible and near infrared a high resolution spectrophotometer was. The proposed mathematical model was developed in a regression procedure using gauss-sigmoid type function. The dependent variable was the intensity of the recorded optical signals. In order to estimate the optimal parameters of the model an evolutionary algorithm was used. The optimization procedure was performed in Matlab environment. For determination of the matching quality of theoretical parameters of the regression function to the empirical data determination coefficient $\mathrm{R}^{2}$ was applied.
\end{abstract}

\section{Introduction}

One of the most important areas of research activities is elaboration of mathematical models which can be used for mathematical description of objects, technical and technological process and physical phenomena.

The application of mathematical modeling requires thorough knowledge of the analyzed physical phenomena and the appropriate selection of mathematical tools that will allow description of the phenomenon and estimation of the parameters of the applied equation [1].

Generation of electrical discharges in the insulating oils is accompanied by physical phenomena. The most important of these are: ultra-high frequency (UHF) [2,3], acoustic wave generation (AE) [4-7], optical radiation [8-10] and high-energy X-rays [11,12]. Based on these phenomena, measurement methods have been applied, which are used in diagnostics of insulation systems in power transformers [13-15].

As part of the work a parametric model has been developed, which describes the recorded spectral distributions of the emitted optical radiation for all investigated forms of electrical discharges (ED). The emitted optical radiation was recorded during the ED generation in the following systems: point-point, pointplate, surface discharges.

Measurements of the optical radiation were carried out using the high-resolution optical spectrophotometer HR 4000 manufactured by Ocean Optics that enables registration of optical signals in the radiation range UVVIS-NIR (200 nm - $1100 \mathrm{~nm})$. The light signal was delivered to the spectrophotometer using optic-fibre made of polymer fibre - POF type (Polymer Optical Fibre)[16-19].

The envelope of the optical spectrum was determined by separating the maximum values that were then interpolated with the nonlinear function to obtain a set of data corresponding to the recorded characteristics.

In the process of estimation model sigmoidalgaussian regression function has been used. The dependent variable was the intensity of the recorded optical signals. The independent variable was the wavelength component. The model was based on a literature review [20,21].

Curently in research works to determine the function parameters evolutionary algorithms (EA) are commonly used. They are based on a stochastic search. EA as opposed to other methods are characterized by the following features $[22,23]$ :

- possibility of solving tasks with complicated structure,

- possibility to use for tasks requiring complex parallel computing,

- allow to take into account limitations occurring for the analyzed space,

- simple implementation of a genetic algorithm that does not require extensive mathematical procedures.

Evolutionary methodology unfortunately is not devoid of defects, which can be counted [24]:

- lower efficiency of genetic algorithms compared to traditional gradient algorithms,

- complicated genetic algorithms require precise definition of a number of parameters that need to be implemented individually for each task,

\footnotetext{
* Corresponding author: m.koziol@po.opole.pl
} 
- when each time the algorithm is run in the task, it usually causes some other solutions.

Process of creating a model consists of:

- analysis of the construction of an object or phenomenon,

- observation of mechanisms of occurrence of the analyzed phenomenon,

- selection of appropriate mathematical tools,

- verification of the created model by comparing its response with the input value.

\section{Model of sigmoidal-gaussian regression function}

Model of sigmoidal-gaussian regression function is described by equation (1):

$$
\operatorname{MSG}(\lambda)=\frac{A}{1+k e^{-(\lambda-\mu)}} \sum_{i=1}^{n} a_{i} e^{-\left(\frac{\lambda-\mu_{i}}{c_{i}}\right)^{2}}
$$

where:

$\operatorname{MSG}(\lambda)$ - approximation of the sigmoidal-gaussian regression function,

$\lambda \in \mathbb{R}$ - wavelength,

$\left(A, a_{i}\right) \in \mathbb{R}$ - estimates of structural parameters, intensity,

$k>0$ - estimation of the structural parameter, rising,

$c_{i}>0$ - estimation of structural parameter, scale,

$\left(\mu, \mu_{i}\right) \in \mathbb{R}$ - estimates of structural parameters, location,

$n$-number of dominant components in spectral distribution.

The genetic algorithm available in the Matlab environment has been used to estimate optimal parameters of the optical spectrum model [25].

Based on the trial simulations and computing capabilities of the available hardware ,the following parameters of the genetic algorithm were adopted:

- number of designated variables: $15-18$,

- number of generations: 1000 ,

- population size: 300 ,

- initial values: selected globally,

- Scope of the search: globally defined.

To determine the measure of matching regression function parameters with empirical values the determination coefficient $\mathrm{R}^{2}$ was used (2) [26-28]:

$$
R^{2}=\left(\frac{\sum_{\forall i}\left(x_{i}-\mu\right)\left(\tilde{x}_{i}-\tilde{\mu}\right)}{\sqrt{\sum_{\forall i}\left(x_{i}-\mu\right)^{2} \sum_{\forall i}\left(\tilde{x}_{i}-\tilde{\mu}\right)^{2}}}\right)^{2}
$$

where:

$x_{i}$ - the value of the empirical dependent variable,

$\tilde{x}_{i}-$ the theoretical value (estimated) of the distribution,

$\mu$-arithmetic mean of the empirical dependent variable,

$\tilde{\mu}^{-}$the theoretical arithmetical mean of the distribution,

$i=(1,2, \ldots, n), n=3648$ - number of components that fall within one spectral distribution.

\section{Applicability analysis of MSG model}

\subsection{Measuring conditions}

Optical spectral recording was performed for three spark gaps systems: point-point, point-plate and surface discharges. Electrical discharges was generated for the alternating voltage (AC) and for three technical conditions of mineral oil: pure mineral oil, operated (used) mineral oil, operated mineral oil with air bubbles. During the measurements for point-point and point-plate type systems, the distance between the electrodes was constant and amounted to $6 \mathrm{~mm}$. The electrodes for surface discharges type system were separated by a dielectric, which was a glass plate of $10 \mathrm{~mm}$ thickness.

The value of breakdown voltage $\left(\mathrm{U}_{\mathrm{b}}\right)$ was defined for each spark gap system, before starting the measurements. Values of breakdown voltage for the applied spark gap are presented in Table 1.

Optical signals were recorded using a high-resolution optical spectrophotometer HR4000. To transmit the optical signals from spark gap systems to the spectrophotometer, optical fiber was used.

Table 1. Values of breakdown voltage for the applied spark gap systems.

\begin{tabular}{|c|c|c|c|}
\hline \multirow{2}{*}{$\begin{array}{c}\text { Spark gap } \\
\text { systems }\end{array}$} & \multicolumn{3}{|c|}{ Values of breakdown voltage $\mathbf{U}_{\mathbf{b}}[\mathrm{kV}]$} \\
\cline { 2 - 4 } & $\begin{array}{c}\text { Brand } \\
\text { new } \\
\text { mineral } \\
\text { oil }\end{array}$ & $\begin{array}{c}\text { Operated } \\
\text { (used) } \\
\text { mineral oil }\end{array}$ & $\begin{array}{c}\text { Operated } \\
\text { mineral oil } \\
\text { with air } \\
\text { bubbles }\end{array}$ \\
\hline point-point & 48.5 & 45.6 & 44.8 \\
\hline point-plate & 47.5 & 45.2 & 46.3 \\
\hline $\begin{array}{c}\text { Surface } \\
\text { discharges }\end{array}$ & 49.8 & 49.8 & 49.8 \\
\hline
\end{tabular}

\subsection{Application of the MSG model}

The adopted model (MSG) was used to describe the optical emission distribution emitted by the ED generated in the point-point system for the three electrolytic insulating oils studied: pure mineral oil, exploited mineral oil, exploited mineral oil with air bubbles.

For comparison and reproduction of the results of measurements and analysis of the optical signals generated by the tested ED forms, the relative voltage values was applied. The relative voltage value was referred to brekdown voltage $\left(\mathrm{U}_{\mathrm{b}}\right)$, which was determined for each of the spark gap systems.

Degree of matching models to the registered spectrum of optical radiation were analyzed for a relative supply voltage in the range of $0.60 \mathrm{U}_{\mathrm{b}}$ to $0.95 \mathrm{U}_{\mathrm{b}}$, with a graduation rate of $0.05 \mathrm{U}_{\mathrm{b}}$ separately for each of the three tested insulating oils.

Fig. 1-3 show exemplary spectrum distributions of optical radiation, Recorded by optical spectrophotometry (blue color) and models (red color), emitted by ED in the tested insulating oils: pure (fig. 1), operated (fig. 2) and operated with air bubbles (Fig. 3). For comparative purposes, the numerical values of determinants of $\mathrm{R}^{2}$ for the MSG model are summarized in Tables 2-4. 


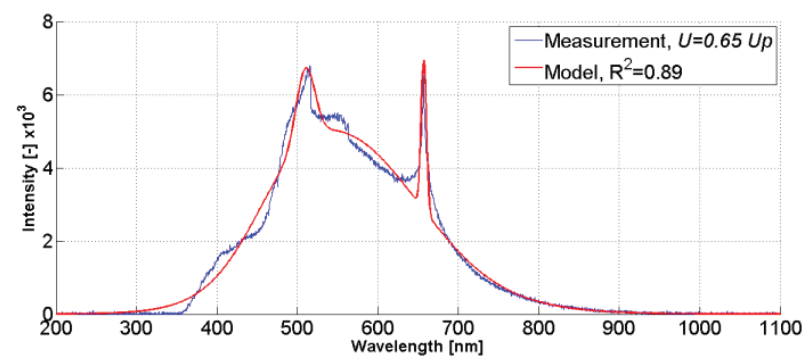

Fig. 1. Distribution of the spectrum of recorded optical radiation (blue color) and modeled (red) emitted by the ED generated in the point-point system in pure mineral oil for a relative supply voltage value of $0.65 \mathrm{U}_{\mathrm{b}}$.

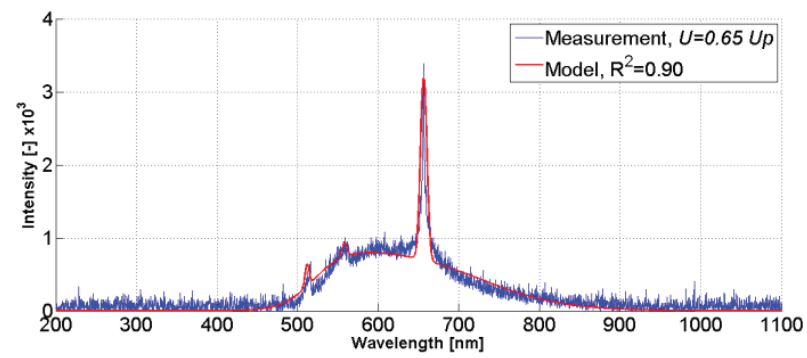

Fig. 2. Distribution of the spectrum of recorded optical radiation (blue color) and modeled (red) emitted by the ED generated in the point-point system in operated mineral oil for a relative supply voltage value of $0.65 \mathrm{Ub}$.

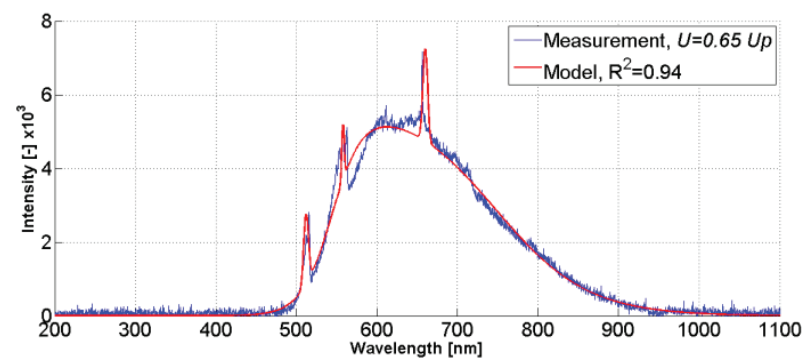

Fig. 3. Distribution of the spectrum of recorded optical radiation (blue color) and modeled (red) emitted by the ED generated in the point-point system in operated mineral oil with air bubbles for a relative supply voltage value of $0.65 \mathrm{U}_{\mathrm{b}}$.

Table 2. Mean values of the determination factor $\mathrm{R}^{2}$ calculated for the model (MSG) used in the point-point system, for the three tested insulating oils.

\begin{tabular}{|c|c|c|c|}
\hline \multirow[b]{2}{*}{$\begin{array}{c}\text { Relative } \\
\text { voltage } \\
\text { value }\end{array}$} & \multicolumn{3}{|c|}{ Value of determination coefficient $R^{2}$} \\
\hline & $\begin{array}{c}\text { Brand } \\
\text { new } \\
\text { mineral } \\
\text { oil } \\
\end{array}$ & $\begin{array}{l}\text { Operated } \\
\text { (used) } \\
\text { mineral oil }\end{array}$ & $\begin{array}{c}\text { Operated } \\
\text { mineral oil } \\
\text { with air } \\
\text { bubbles }\end{array}$ \\
\hline 0.60 & 0.84 & 0.82 & 0.91 \\
\hline 0.65 & 0.87 & 0.91 & 0.95 \\
\hline 0.70 & 0.86 & 0.96 & 0.84 \\
\hline 0.75 & 0.95 & 0.93 & 0.93 \\
\hline 0.80 & 0.92 & 0.90 & 0.90 \\
\hline 0.85 & 0.96 & 0.89 & 0.87 \\
\hline 0.90 & 0.93 & 0.94 & 0.96 \\
\hline 0.95 & 0.92 & 0.89 & 0.88 \\
\hline Median & 0.92 & 0.90 & 0.90 \\
\hline $\begin{array}{c}\text { Arithmetic } \\
\text { average }\end{array}$ & 0.91 & 0.90 & 0.90 \\
\hline $\begin{array}{l}\text { Standard } \\
\text { deviation }\end{array}$ & 0.04 & 0.04 & 0.04 \\
\hline
\end{tabular}

The determined $\mathrm{R}^{2}$ values for individual power supply values were averaged (arithmetic mean) from the 15 analyzed measurements for each case.

In an analogous manner, the adopted model (MSG) was used to describe the distribution of emitted optical radiation generated by ED in the point-plate system and in the surface discharge system for all tested insulating oils. Examples of spectral distributions of optical radiation are presented in Fig. 4-9.

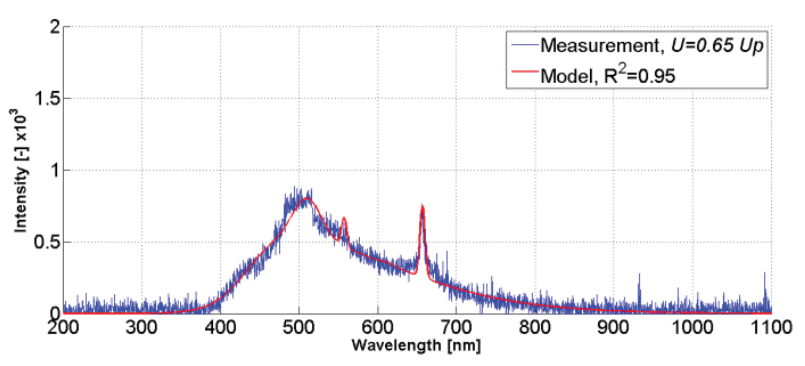

Fig. 4. Distribution of the spectrum of recorded optical radiation (blue color) and modeled (red) emitted by the ED generated in the point-plate system in pure mineral oil for a relative supply voltage value of $0.65 \mathrm{U}_{\mathrm{b}}$

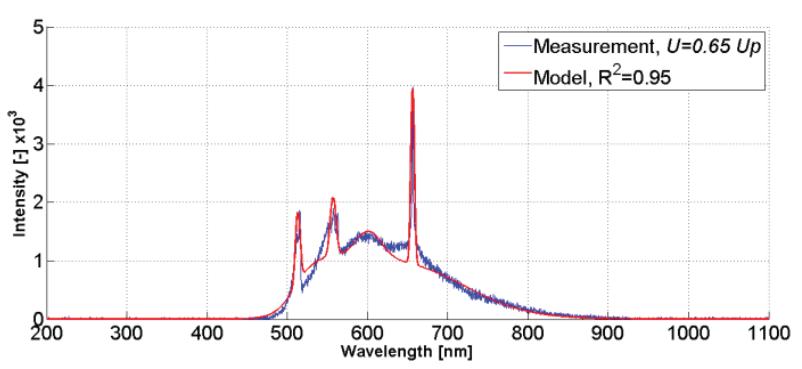

Fig. 5. Distribution of the spectrum of recorded optical radiation (blue color) and modeled (red) emitted by the ED generated in the point-plate system in operated mineral oil for a relative supply voltage value of $0.65 \mathrm{U}_{\mathrm{b}}$.

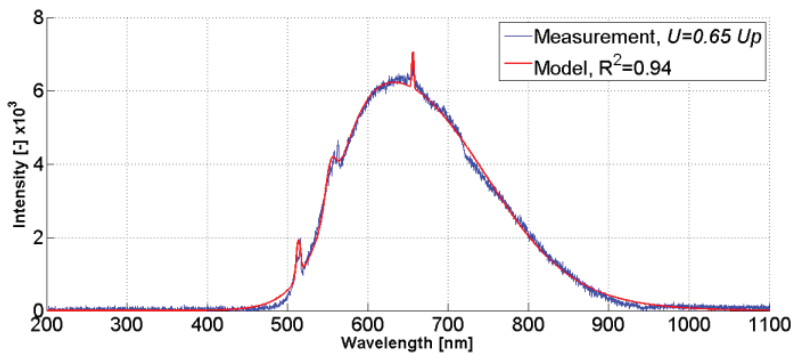

Fig. 6. Distribution of the spectrum of recorded optical radiation (blue color) and modeled (red) emitted by the ED generated in the point-point system in operated mineral oil with air bubbles for a relative supply voltage value of $0.65 \mathrm{Ub}$. 
Table 3. Mean values of the determination factor $\mathrm{R}^{2}$ calculated for the model (MSG) used in the point-plate system, for the three tested insulating oils.

\begin{tabular}{|c|c|c|c|}
\hline \multirow[b]{2}{*}{$\begin{array}{c}\text { Relative } \\
\text { voltage } \\
\text { value }\end{array}$} & \multicolumn{3}{|c|}{ Value of determination coefficient $R^{2}$} \\
\hline & $\begin{array}{c}\text { Brand } \\
\text { new } \\
\text { mineral } \\
\text { oil } \\
\end{array}$ & $\begin{array}{l}\text { Operated } \\
\text { (used) } \\
\text { mineral oil }\end{array}$ & $\begin{array}{c}\text { Operated } \\
\text { mineral oil } \\
\text { with air } \\
\text { bubbles }\end{array}$ \\
\hline 0.60 & 0.92 & 0.89 & 0.91 \\
\hline 0.65 & 0.91 & 0.94 & 0.93 \\
\hline 0.70 & 0.95 & 0.91 & 0.96 \\
\hline 0.75 & 0.94 & 0.93 & 0.94 \\
\hline 0.80 & 0.96 & 0.92 & 0.95 \\
\hline 0.85 & 0.91 & 0.90 & 0.97 \\
\hline 0.90 & 0.89 & 0.87 & 0.96 \\
\hline 0.95 & 0.90 & 0.94 & 0.95 \\
\hline Median & 0.91 & 0.91 & 0.95 \\
\hline $\begin{array}{l}\text { Arithmetic } \\
\text { average }\end{array}$ & 0.92 & 0.91 & 0.95 \\
\hline $\begin{array}{l}\text { Standard } \\
\text { deviation }\end{array}$ & 0.02 & 0.02 & 0.02 \\
\hline
\end{tabular}

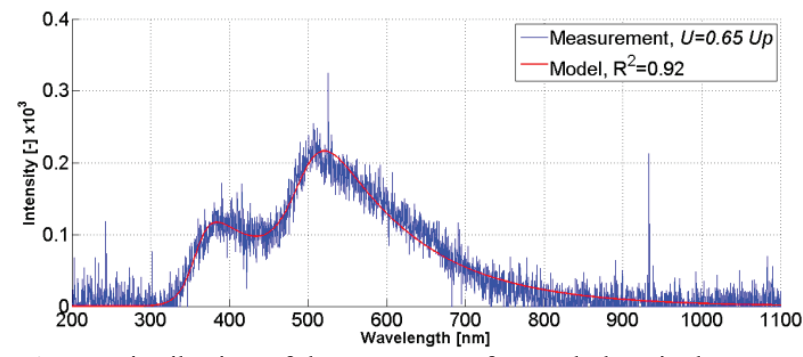

Fig. 7. Distribution of the spectrum of recorded optical radiation (blue color) and modeled (red) emitted by the ED generated in the surface discharge system in pure mineral oil for a relative supply voltage value of $0.65 \mathrm{Ub}$.

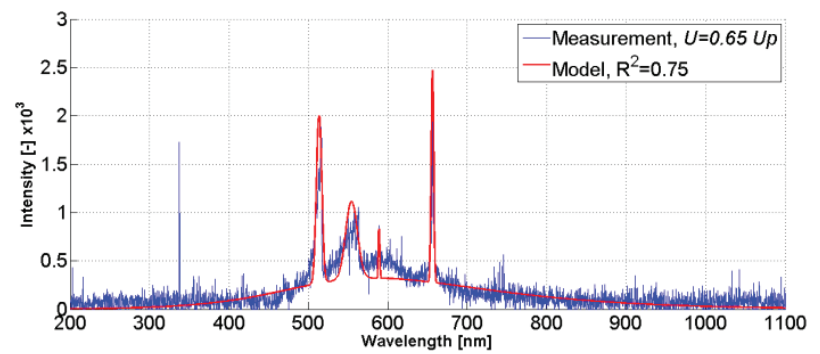

Fig. 8. Distribution of the spectrum of recorded optical radiation (blue color) and modeled (red) emitted by the ED generated in the surface discharge system in operated mineral oil for a relative supply voltage value of $0.65 \mathrm{Ub}$.

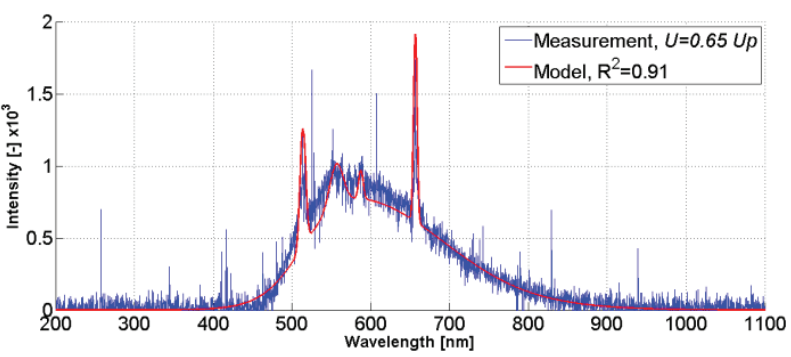

Fig. 9. Distribution of the spectrum of recorded optical radiation (blue color) and modeled (red) emitted by the ED generated in the surface discharge system in operated mineral oil with air bubbles for a relative supply voltage value of $0.65 \mathrm{Ub}_{\mathrm{b}}$.
Table 4. Mean values of the determination factor $\mathrm{R}^{2}$ calculated for the model (MSG) used in the surface discharge system, for the three tested insulating oils.

\begin{tabular}{|c|c|c|c|}
\hline \multirow[b]{2}{*}{$\begin{array}{c}\text { Relative } \\
\text { voltage } \\
\text { value }\end{array}$} & \multicolumn{3}{|c|}{ Value of determination coefficient $R^{2}$} \\
\hline & $\begin{array}{c}\text { Brand } \\
\text { new } \\
\text { mineral } \\
\text { oil }\end{array}$ & $\begin{array}{l}\text { Operated } \\
\text { (used) } \\
\text { mineral oil }\end{array}$ & $\begin{array}{c}\text { Operated } \\
\text { mineral oil } \\
\text { with air } \\
\text { bubbles }\end{array}$ \\
\hline 0.60 & 0.91 & 0.79 & 0.83 \\
\hline 0.65 & 0.97 & 0.85 & 0.96 \\
\hline 0.70 & 0.98 & 0.87 & 0.91 \\
\hline 0.75 & 0.97 & 0.90 & 0.89 \\
\hline 0.80 & 0.96 & 0.90 & 0.87 \\
\hline 0.85 & 0.97 & 0.94 & 0.91 \\
\hline 0.90 & 0.95 & 0.85 & 0.89 \\
\hline 0.95 & 0.94 & 0.84 & 0.90 \\
\hline Median & 0.96 & 0.86 & 0.89 \\
\hline $\begin{array}{c}\text { Arithmetic } \\
\text { average }\end{array}$ & 0.96 & 0.87 & 0.89 \\
\hline $\begin{array}{l}\text { Standard } \\
\text { deviation }\end{array}$ & 0.02 & 0.05 & 0.04 \\
\hline
\end{tabular}

\section{Comparative analysis of the obtained results}

For comparative purposes, Figs. 10-12 show arithmetic mean and median values for determinants $R^{2}$, separately for each of the three tested insulating oils.

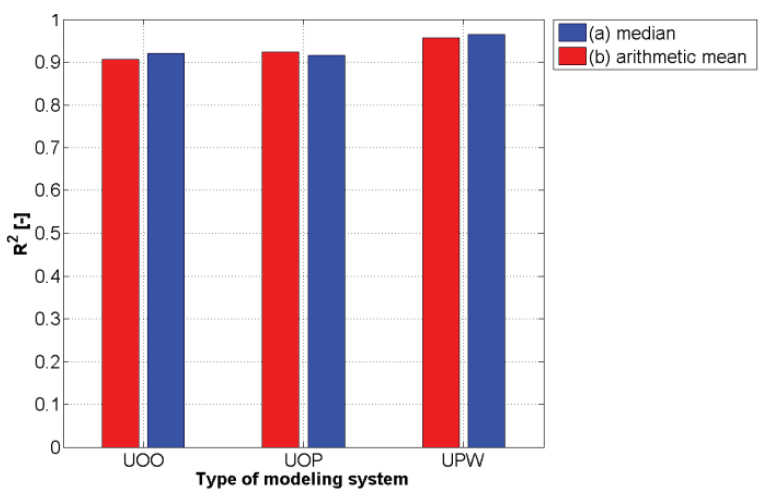

Fig. 10. Median (a) and arithmetic mean (b) of $R^{2}$, calculated for ED generating systems: point-point (UOO), point-plate (UOP) and surface discharge system (UPW); generated in pure mineral oil.

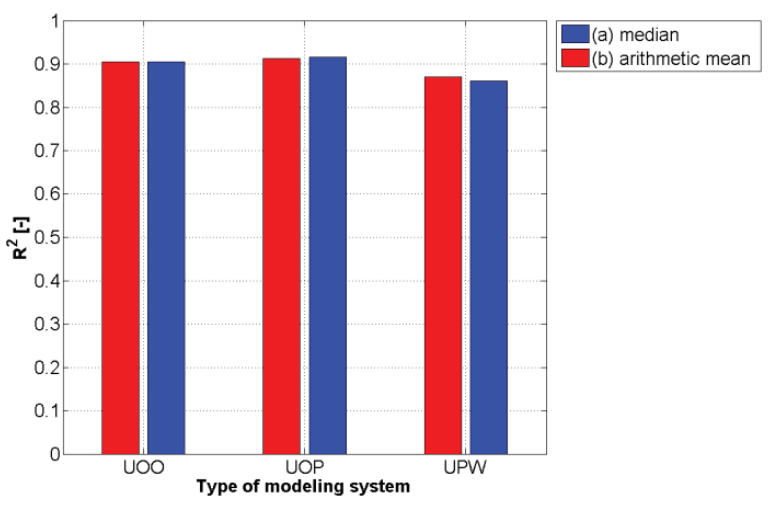

Fig. 11. Median (a) and arithmetic mean (b) of $R^{2}$, calculated for ED generating systems: point-point (UOO), point-plate (UOP) and surface discharge system (UPW); generated in operated mineral oil. 


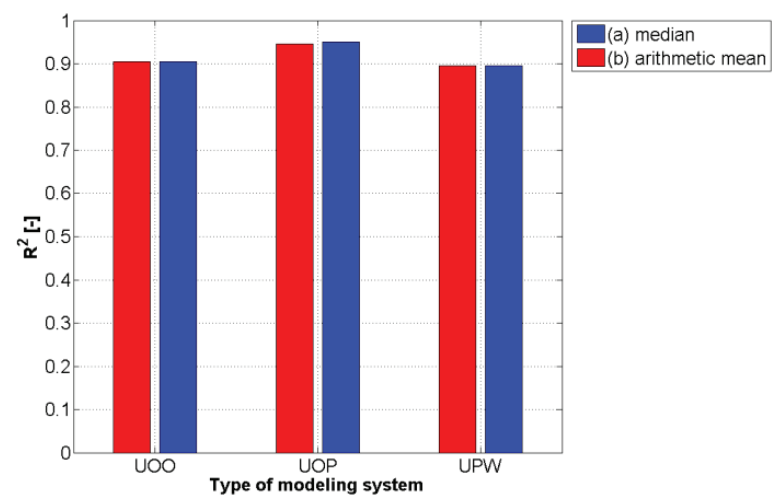

Fig. 12. Median (a) and arithmetic mean (b) of $R^{2}$, calculated for ED generating systems: point-point (UOO), point-plate (UOP) and surface discharge system (UPW); generated in operated mineral oil with air bubbles.

Based on the comparative analysis of the determinants of $\mathrm{R}^{2}$, it can be concluded that the applied mathematical model (MSG) is characterized by good and very good matching of parameters to empirical values, which is confirmed by arithmetic meanings within the range of $0.8-1.0$.

Mathematical model for the entire range of the emitted optical signal consists of the models components sum of optical spectrum structures. These structures consist of: continuous spectrum, which is described by the sigmoid function and band spectrum, described by the Gaussian function.

The model obtained can be finally described using function (3). The most important parameter of this dependence of coefficient values are: $\mu_{11}, \mu_{12}, \mu_{13}$. Based on them, it is possible to determine the dominant component wavelengths present in the analyzed spectral range.

$$
\begin{gathered}
\operatorname{MSG}(\lambda)=\left(\frac{A_{1}}{\left.1+k_{1} e^{-\left(\lambda-\mu_{1}\right)}\right)}\right)\left(\frac{A_{2}}{\left.1+k_{2} e^{-\left(\lambda-\mu_{2}\right)}\right)}\right) \\
+\left(a_{11} e^{-\left(\frac{\lambda-\mu_{11}}{c_{11}}\right)^{2}}\right)+\left(a_{12} e^{-\left(\frac{\lambda-\mu_{12}}{c_{12}}\right)^{2}}\right) \\
+\left(a_{13} e^{-\left(\frac{\lambda-\mu_{13}}{c_{13}}\right)^{2}}\right)
\end{gathered}
$$

Values of equation (3) were determined in the optimization process using a genetic algorithm (GA) implemented in a Matlab environment. Tables 5-6 shows the sample values of parameters that were calculated for the spectral distribution of the optical radiation emitted in the point-point system.

Table 5. Examples of mathematical model parameters (MSG)

\begin{tabular}{|c|c|c|c|}
\hline $\begin{array}{c}\text { Parameter } \\
\text { type }\end{array}$ & $\begin{array}{c}\text { Parameter } \\
\text { value }\end{array}$ & $\begin{array}{c}\text { Parameter } \\
\text { type }\end{array}$ & $\begin{array}{c}\text { Parameter } \\
\text { value }\end{array}$ \\
\hline $\mathrm{A}_{1}$ & 3.35 & $\mathrm{a}_{11}$ & 5.70 \\
\hline $\mathrm{k}_{1}$ & 0.03 & $\mu_{11}$ & 514.96 \\
\hline$\mu_{1}$ & 510.54 & $\mathrm{c}_{11}$ & 10.11 \\
\hline $\mathrm{A}_{2}$ & 3.60 & & \\
\hline $\mathrm{k}_{2}$ & 0.01 & & \\
\hline$\mu_{2}$ & 722.89 & & \\
\hline
\end{tabular}
values determined for the entire spectral range of emitted radiation generated in the point-point system.
Table 6. Examples of mathematical model parameters (MSG) values determined for the entire spectral range of emitted radiation generated in the point-point system.

\begin{tabular}{|c|c|c|c|}
\hline $\begin{array}{c}\text { Parameter } \\
\text { type }\end{array}$ & $\begin{array}{c}\text { Parameter } \\
\text { value }\end{array}$ & $\begin{array}{c}\text { Parameter } \\
\text { type }\end{array}$ & $\begin{array}{c}\text { Parameter } \\
\text { value }\end{array}$ \\
\hline $\mathrm{a}_{12}$ & 1.50 & $\mathrm{a}_{13}$ & 1.02 \\
\hline$\mu_{\mathbf{1 2}}$ & $\mathbf{5 6 2 . 0 5}$ & $\boldsymbol{\mu}_{\mathbf{1 3}}$ & $\mathbf{6 5 6 . 1 0}$ \\
\hline $\mathrm{c}_{12}$ & 7.72 & $\mathrm{c}_{13}$ & 4.99 \\
\hline
\end{tabular}

Based on the obtained values of determinants of $\mathrm{R}^{2}$, it can be concluded that the proposed model (MSG) and the procedures used to determine its parameters were chosen correctly. The model can be used to determine the dominant values of wavelength components. This makes it possible to apply an adopted mathematical model to a data block that may be a part of an expert system.

\section{Conclusions}

The purpose of creating mathematical models is to describe the behavior of a model object as an influencing factor. Such description allows to predict the behavior of an object with changes in influencing factors. As a result, is possible to analyze and design objects using only their mathematical description or simulation model.

Proposed in this paper mathematical model for describing optical signals emitted by electrical discharges in insulating oil can be used to build the knowledge base.

Obtained results with optical signal modeling can also be used to build a database consisting of comparative patterns of emited optical spectra. Such a solution can be a component for designing an expert system that will be dedicated to diagnostics of high voltage insulation systems.

\section{References}

1. J.M. González-Barrios, S. Ruiz-Velasco, Metrika 61 (2005)

2. S.M. Hoek, A. Kraetge, M. Koch, O. Kessler, M. Heindl, in Proc. of 2012 IEEE Int. Conf. Condition Monit. and Diagnosis, CMD $2012 \quad$ (2012) doi:10.1109/CMD.2012.6416438

3. S. Coenen, S. Tenbohlen, IEEE Trans. Dielectr. Electr. Insul. 19 (2012)

4. T. Boczar, A. Cichoń, S. Borucki, IEEE Trans. Dielectr. Electr. Insul. 21 (2014)

5. M. Kunicki, A. Cichoń, S. Borucki, Arch. Acoust. 41 (2016)

6. G. Kil, D. Park, I. Kim, S. Choi, WSEAS Trans. Power Syst. 3 (2008)

7. H. Majchrzak, A. Cichoń, S. Borucki, Arch. Acoust. 42 (2017)

8. P. Frącz, T. Boczar, D. Zmarzly, T. Szczyrba, in Acta Phys. Pol. A 124 (2013)

9. P. Rózga, P. Tabaka, in 2015 IEEE 11th Int. Conf. 
Prop. Appl. of Dielectr. Mater. (ICPADM, 2015)

10. D. Siebler, P. Rohwetter, R. Brusenbach, R. Plath, Procedia Eng. 120 (2015)

11. Ł. Nagi, D. Zmarzly, T. Boczar, P. Frącz, IEEE Trans. Dielectr. Electr. Insul. 23 (2016)

12. S. Adili, L. G. Herrmann, C. M. Franck, in Annual Report - Conf. Electr. Insul. Dielectr. Phenom., CEIDP (2012) doi:10.1109/CEIDP.2012.6378737

13. Z. Nadolny, G. Dombek, P. Przybylek, in IEEE Conf. Electr. Insul. Dielectr. Phenom. (2016)

14. P.M. Mitchinson, P.L. Lewin, P. Jarman, IEEE Electr. Insul. Mag. 29 (2013)

15. T. Boczar, A. Cichon, D. Wotzka, M. Kunicki, M. Koziol, IEEE Trans. Dielectr. Electr. Insul. 24 (2017)

16. M. Kozioł, D. Wotzka, T. Boczar, P. Frącz, J. Spectrosc. 2016 (2016)

17. T. Boczar, D. Zmarzly, P. Frącz, IEEE 11th Int. Conf. Prop. Appl. Dielectr. Mater. (2015) doi:10.1109/ICPADM.2015.7295378

18. T. Boczar, D. Zmarzly, in IEEE Int. Conf. Dielectr.
Liq. (2005) doi:10.1109/ICDL.2005.1490036

19. S. Biswas, C. Koley, B. Chatterjee, S. Chakravorti, IEEE Trans. Dielectr. Electr. Insul. 19 (2012)

20. J. Saragih, in Proc. of the IEEE Comput. Soc. Conf. Comput. Vision and Pattern Recognit. (2011) doi:10.1109/CVPR.2011.5995618

21. D. Wotzka, A. Cichoń, T. Boczar, Arch. Acoust. 37 (2012)

22. T. Bartz-Beielstein, J. Branke, J. Mehnen, O. Mersmann, Wiley Interdiscip. Rev. Data Min. Knowl. Discovery 4 (2014)

23. C. Gagn, J. Mach. Learn. Res. 13 (2012)

24. L. Dioşan, M. Oltean, Genet. Program. Evolvable Mach. 10 (2009)

25. M. Kumar, M. Husian, N. Upreti, D. Gupta, Int. J. Inf. Technol. Knowl. Manag. 2 (2010)

26. O. Harel, J. Appl. Stat. 36 (2009)

27. R. Anderson-Sprecher, Am. Stat. 48 (1994)

28. R. C. Quinino, E. A. Reis, L. F. Bessegato, Teach. Stat. 35 (2013) 